\title{
Making use of Life Cycle Assessment and Environmental Product Declarations - a survey with practitioners
}

Galindro, Bruno Menezes; Welling, Sebastian ; Bey, Niki; Olsen, Stig Irving; Soares, Sebastião Roberto; Ryding, Sven-Olof

Published in:

Journal of Industrial Ecology

Link to article, DOI:

$10.1111 /$ jiec. 13007

Publication date:

2020

Document Version

Peer reviewed version

Link back to DTU Orbit

Citation (APA):

Galindro, B. M., Welling, S., Bey, N., Olsen, S. I., Soares, S. R., \& Ryding, S-O. (2020). Making use of Life Cycle Assessment and Environmental Product Declarations - a survey with practitioners. Journal of Industrial Ecology, 24(5), 965-975. https://doi.org/10.1111/jiec.13007

\section{General rights}

Copyright and moral rights for the publications made accessible in the public portal are retained by the authors and/or other copyright owners and it is a condition of accessing publications that users recognise and abide by the legal requirements associated with these rights.

- Users may download and print one copy of any publication from the public portal for the purpose of private study or research.

- You may not further distribute the material or use it for any profit-making activity or commercial gain

- You may freely distribute the URL identifying the publication in the public portal 
Journal of industrial ecology, 2020

Article Type: Forum

Title: Making use of Life Cycle Assessment and Environmental Product Declarations - a survey with practitioners

Authors: Bruno Menezes Galindro ${ }^{1,2}$, Sebastian Welling ${ }^{3}$, Niki Bey ${ }^{4}$, Stig Irving Olsen ${ }^{4}$, Sebastião Roberto Soares ${ }^{2}$, Sven-Olof Ryding ${ }^{3}$

\section{Institutions:}

${ }^{1}$ Instituto Federal de Educacão, Ciência e Tecnologia de Santa Catarina - IFSC - Gaspar, Brazil

${ }^{2}$ Department of Environmental Engineering - Federal University of Santa Catarina - UFSC Florianópolis, Brazil

${ }^{3}$ IVL Swedish Environmental Research Institute, Stockholm, Sweden

${ }^{4}$ Sustainability Division, Department of Technology, Management and Economics, Technical University of Denmark - DTU, Kgs. Lyngby, Denmark.

Corresponding Authors:

Bruno M. Galindro. Rua Adriano Kormann, 510 - 89111009 - Gaspar, Santa Catarina, Brazil. bruno.menezes@ifsc.edu.br

Sebastian Welling. Valhallavägen 81, 11427 Stockholm, Sweden. sebastian.welling@ivl.se

Conflict of Interest Statement: The authors declare no conflict of interest.

Keywords: Life Cycle Assessment, Environmental Product Declarations, benchmarking, communication, industrial ecology.

Abstract: Life Cycle Assessment (LCA) and Environmental Product Declarations (EPDs) represent important sources of information in applications such as ecodesign and process optimization. However, their use in comparisons and communication is still limited. Therefore, this article aims to understand the use of LCA- and EPD-information from the perspective of the practitioners i.e. professionals with experience in dealing with this type of information. A survey was built consisting of two questionnaires and two webinars, with questions related to core themes: frequency and purpose of use, comparability, advantages and disadvantages for practical use and reliability of different presentation formats. Also, two suggested benchmarking frameworks were presented and discussed, later being commented upon and evaluated. Out of the 55 respondents, $76 \%$ stated that they use both LCA- and EPD- information, primarily to fulfill requirements from customers, in environmental management systems and for marketing 
47 purposes. It was also stated that they use LCA- (73\%) and EPD- (56\%) information to make 48 comparisons but presented different responses and there were no established patterns as to the 49 procedures. Methodological limitations and the need of harmonization of Product Category

50 Rules (PCRs) were mentioned as limiting factors for comparisons between studies. Regarding

51 the benchmarking frameworks, both were indicated to be potentially applicable in

52 communication with consumers and between companies. It is concluded that LCA- and EPD-

53 information is used by the practitioners in different applications, and that there may be a need to

54 increase standardization efforts of benchmarking procedures, in order to improve communication

55 with non-specialist audiences.

56

57 


\section{INTRODUCTION}

International standards for Life Cycle Assessments (LCA) (ISO, 2006b; c) lay the foundation for the calculation of the environmental performance of products and services in accordance with a life cycle perspective. This robust set of methodologies, established over more than 30 years of scientific research development, is capable of providing reliable information for the generation of potential environmental impacts of a given production chain (Guinée, 2002; Hauschild, Rosenbaum, \& Olsen, 2018). Throughout this period, companies, researchers, practitioners and other stakeholders have been using information resulting from LCA in different applications such as research and development, ecodesign, process improvements and the identification of hotspots. However, in terms of communication and enabling the comparability of the results from different studies, LCA information still has issues that need improvement in order for the methodology to be even more recognized and expanded (Molina-Murillo \& Smith, 2009; Reap, Roman, Duncan, \& Bras, 2008; Testa, Nucci, Tessitore, Iraldo, \& Daddi, 2016). In this study, the term LCA-information is used for the results from LCA studies and its application to be applied in external communication and comparisons. As stated in the standards for LCA (ISO, 2006b; c), certain criteria shall be fulfilled in order to allow for this type of application. Regarding LCA-information from products, one of the attempts to address these criteria was through the standardization of environmental labelling in the ISO 14020 series of standards (ISO, 2000), especially for Type III declarations, called Environmental Product Declarations (EPDs) (Ibáñez-Forés, Pacheco-Blanco, Capuz-Rizo, \& Bovea, 2016). EPDs are based on underlying LCA studies, which follow common calculation rules and are verified by a third-party.

The principles and requirements to develop and publish EPDs are described in ISO 14025 (ISO, 2006a). LCA studies for EPDs must follow specific calculation rules defined in the socalled Product Category Rules (PCRs) (Del Borghi, 2013; Ingwersen \& Stevenson, 2012). A PCR is developed for a specific product category and contains, for example, criteria for goal and scope definition, allocation procedures, cut-off criteria and selected databases for generic data, which are fundamental elements to ensure the comparability of the EPD-information (Bovea, Ibáñez-Forés, \& Agustí-Juan, 2014; Del Borghi, 2013; Modahl, Askham, Lyng, Skjerve-

Nielssen, \& Nereng, 2013; Stevenson \& Ingwersen, 2012). The term EPD-information is applied within this article to mean the results of the underlying LCA study, published according to the rules for EPDs as defined in ISO 14025.

Despite the advances made through the criteria established by PCRs, there are still challenges to enable comparability between different products and communication of the results of EPDs. The first issue refers to the need to increase the harmonization of PCRs from different program operators (Del Borghi, 2013; Fet, Skaar, \& Michelsen, 2009; Hunsager, Bach, \& Breuer, 2014; Ingwersen \& Stevenson, 2012; Minkov, Schneider, Lehmann, \& Finkbeiner, 2015, Gelowitz \& McArthur, 2017; Toniolo, Mazzi, Simonetto, Zuliani \& Scipioni, 2019). The second issue is related to the fact that EPDs are technical documents where the information can be difficult to understand by a non-specialist audience (Fet \& Skaar, 2006; Ibáñez-Forés et al., 2016; Modahl et al., 2013; Passer et al., 2015). These issues have also been addressed relating to the use of LCA- information. For example, Rex, Fernqvist and Ryding (2019) indicated that further guidance is needed for the interpretation of the results from an LCA study, and Sala and Andreasson (2017) pointed out that the results need to be presented and visualized better and in understandable ways. Considering that ISO 14025 states that EPD-information is primarily 
intended for business-to-business communication, but nevertheless its use for business-toconsumer communication is also foreseen (ISO, 2006a), it emphasizes the need to improve interpretation and the understanding of the results, especially when aimed at an audience without much knowledge about LCA.

In this sense, initiatives to benchmark results appear as a possible solution to position the environmental performance of a product among its competitors, thereby facilitating communication. However, Galindro, Zanghelini and Soares (2019) show that such initiatives are still seldom and scattered, meeting the specific demands of each category of products or organizations but resulting in a fragmentation of initiatives for the same product type. Brinkmann, Köhler, Boeth and Metzger (2018) point out that stakeholder' expectations on EPDs to function as a benchmarking tool are still not fulfilled. New fields of applications for LCA- and EPD- information have recently emerged in the construction sector, with credits and points granted for building certification schemes such as LEED or BREEAM (Bernardi, Carlucci, Cornaro, \& Bohne, 2017; Gelowitz \& McArthur, 2016). However, the use of EPDs in these certifications in practice is still low (Gelowitz \& McArthur, 2016; Bienert, Geiger, \& Hirsch, 2017).

Thus, it is found that in the current scenario, second hand information regarding the results of a product LCA can be obtained in two ways: by analyzing reports, articles and other documents published individually; or through EPDs, published through a program operator and developed according to PCRs criteria. Considering that the use of EPD- information is newer compared to LCA- information and that the number of products that have their information presented in EPD form is still growing, it is important to identify the contexts of the use of either information in terms of the possibilities, applications and limitations of each format. Although this is not competing information, the option of using one or the other or its possible use in different situations can contribute to a better understanding of the future perspectives of this field.

In order to contribute to the development of solutions to the shortcomings highlighted above, it is important to understand the views of key stakeholders in the production chain, especially those directly involved in the elaboration, development and application of LCA- and EPD-information, namely the practitioners. The way information is used by practitioners and how to improve it are still vital aspects to be explored. The engagement of practitioners in such a process is fundamental to a successful outcome, especially for the validation and application of techniques and different presentation formats, and therefore, are the target audience of this survey instead of other stakeholders, such as consumers or product designers. Thus, the present article seeks to understand the use of LCA- and EPD- information from the point of view of the practitioners. This was achieved by receiving their comments and suggestions on different types of data presentation as well as feedback on two benchmarking frameworks presented. The stakeholders invited to be part of the survey are familiar with LCA- and EPD-information, thereby having good knowledge and know-how for providing different theoretical and practical feedback to the information presented. For this, the paper is structured as follows: Section 2 presents the methodology involved in the application of the survey, Section 3 presents and discusses the results regarding the profile of practitioners and their feedback and Section 4 presents the conclusions and final recommendations. 
A survey was prepared to obtain the opinion of practitioners, basically formed by experienced professionals in working with information from LCAs and EPDs. The group of practitioners covers, for example, researchers, managers, directors, consultants, and advisors from different sectors of society such as business services, government and manufacturing. The practitioners interviewed share similar experiences of using environmental information derived from LCA, either directly or as EPDs.

Three audiences were used as starting points: the large network of the International EPD ${ }^{\circledR}$ System including collaborators and partner companies in several countries around the world; professional groups related to the subject of LCA and EPD in the platform LinkedIn and personal contacts of the authors of this study, which together made up a total of approximately 8000 practitioners. Direct invitations to participate in the survey were sent out by e-mail to 180 practitioners with known experience in the field within the network of the authors. From the contact established by e-mail, newsletters or in posts in the LinkedIn groups, practitioners were also asked to share the invitation to the survey with relevant persons in their own networks. The invitation sent to the target audience included descriptive texts of research activities of interest, with further explanations of the issues addressed, together with a link to the questionnaires, which were made available online in the Google Forms platform. To facilitate the process of getting feedback, the respondents only needed to answer the questions on the platform and submit the answers online to the researchers.

The survey was conducted in four stages: two surveys and two questionnaires, details of which can be found in the Supporting Information section. The first questionnaire contained 26 questions related to core themes: the frequency and purpose of the use of the information, comparability of LCAs and EPDs, advantages and disadvantages of using such information, and the reliability of different types of environmental information. In this sense, different question formats were presented, depending on the need and detail of each of the questions, such as multiple choice, open answers and scale assignments. The practitioners were also directed to different questions, for example, when responding to the question "Do you use LCA and / or EPD information?" the answer could be "Yes, I use both,". If so, the practitioner would have to answer follow-up questions for both subjects, while if the answer was "Yes, I use LCA information", the practitioner would only have to answer questions related to the use of LCA information. Therefore, the number of questions and answers given could vary among the participants.

Following the survey, practitioners were invited to attend and participate in a webinar in which two suggested benchmarking frameworks were presented and discussed according to Galindro, Bey, Olsen, Fries, and Soares (2019) and Welling and Ryding (2019). The participants were able to chat online during the webinar with the authors of the proposals, including both asking questions and giving suggestions. The second questionnaire contained 25 questions, which referred to analyses of different formats of data presentation, future perspectives of use of LCA and EPD information and feedback on the proposals presented at the first webinar. The feedback from both questionnaires was presented in a second webinar where the participants were again able to ask questions and give their feedback on the study. The webinars were recorded and made available later on for those who were not able to participate in real time. Links are also available in the Supporting Information section. The entire process, including questionnaires and webinars, took place from August 2018 to February 2019. 
The feedback given on both questionnaires was assessed and analyzed in Excel spreadsheets. For objective responses, the final percentage of respondents was considered for each of the alternatives presented. Questions with open text feedback were analyzed and grouped in categories by the authors.

\section{THE USE OF LCA- AND EPD- INFORMATION}

The first questionnaire was responded to by a total of 55 practitioners, divided into different sectors of society and their organizational positions. Participants were from 21 different countries with a predominance of Europeans ( $76 \%$ of the respondents). In terms of sectors, business services were the most represented (16\%), followed by manufacturing companies $(15 \%)$ and from governments $(11 \%)$. It is worth noting that $27 \%$ of the practitioners stated to come from other sectors, which were not further specified. As for the organizational positions, most of the practitioners were managers/leaders $(33 \%)$, heads/CEOs $(25 \%)$, researchers $(18 \%)$ or consultants (13\%). See Supporting Material for further details about the profile of the practitioners.

Regarding the use of environmental information, $76 \%$ of the practitioners stated that they use both LCA- and EPD- information, 10\% use LCA- information only, 5\% use EPDinformation only and $10 \%$ do not use either type of information. When asked about the frequency of using this type of information, $43 \%$ stated the use of LCA- and $38 \%$ of EPDinformation daily. A slightly higher frequency of using LCA-information may be noted compared to EPD-information. The share of the participants that use EPD-information weekly $(35 \%)$ is higher than for LCA-information (25\%). Approximately a quarter of the practitioners stated that they use LCA-information (24\%) or EPD-information (21\%) on a monthly basis. Only a minority of practitioners stated that LCA- $(8 \%)$ or EPD-information $(6 \%)$ is used yearly.

Concerning the purpose of using the information, practitioners were given several options and could choose more than one for using both LCA- and EPD-information. In general, both LCA- and EPD-information were indicated with a similar extent of use with small variations between them. The numbers in terms of total responses and percentages of use in all items are presented in Figure 1. Despite the less frequent use of EPD-information, practitioners indicated that both seem to have similar applications. Specifically, the use to "Fulfill requirements from customers" was the most frequently stated option by practitioners for both LCA- (21\%) and EPD-information (23\%), followed by "Environmental management systems" (19\% and 21\% respectively) and "Marketing" (14\% and 16\%, respectively). Other relevant purposes of use such as "Public procurement", "Requirements on suppliers" and "Providing data within programs" were also stated but with less frequent applications. Figure 1 presents the results obtained for the questions regarding the purpose of using the information. 


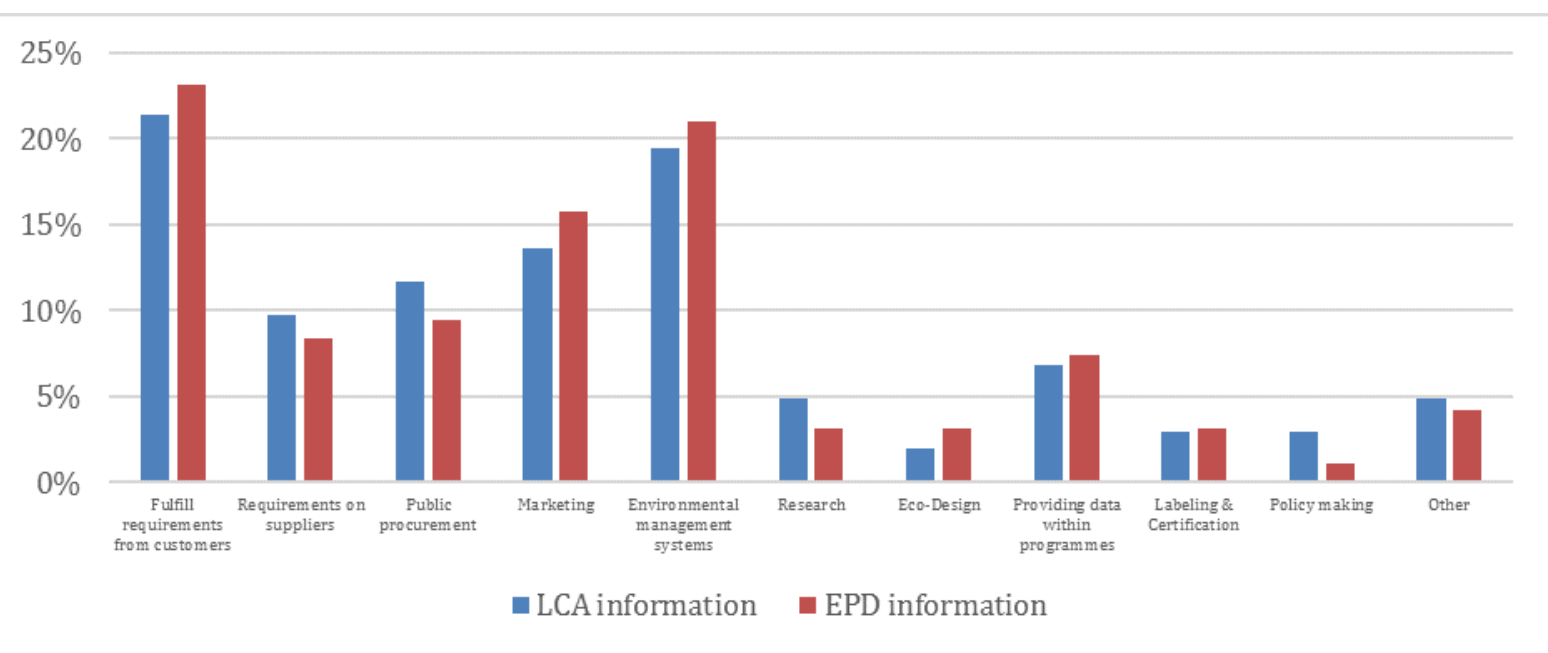

Figure 1. Purpose of using environmental information as stated by the respondents of the questionnaire (in \% of the practitioners). Underlying data used to create this figure can be found in the Supporting Information.

The reasons for using LCA- and EPD- information for these purposes can be clustered into six main categories. The practitioner's position and role in their organizations $(38 \%)$ is by far the most relevant motive for using LCA-information, as it is the same for using EPDinformation but not to the same extent (27\%), this is followed by the need and requirements from the market (24\%) and the quality and credibility of the information (24\%). Improvement of processes and products $(15 \%)$ as well as market needs and requirements (13\%) are additional motives for using LCA information.

Regarding the use of the information for comparisons of the environmental performances between different products, it is noticed that there is a difference in the perception of the practitioners in relation to LCA- and EPD-information. Most of the practitioners used this information to make comparisons both for LCA- and EPD- information. 73\% of the practitioners claimed to use LCA-information for comparisons, while the corresponding use of EPDinformation was less cited (56\%). Methodological limitations, the proliferation of EPD program operators, different calculation assumptions in the studies and the absence of benchmarks were mentioned as some of the reasons for not using EPD-information for comparisons. It is worth noting that $73 \%$ of practitioners claimed to use EPD-information from more than one EPD program operator. Although the initial objective of using EPD-information is to facilitate and enable comparability between the environmental performance of products (as stated in ISO 14025), the results of the questionnaire indicate that the diversity of PCRs created in different EPD programs may contribute to explain the lower use of EPD- information in comparisons. Another possibility that may help explain the stated lower use of EPD-information in comparisons by the practitioners is that they may prefer to make comparisons using their own criteria rather than using what is defined in PCRs. The availability of the types of information studied as well as the time of existence on the market may influence the perceived credibility.

For those practitioners who answered "Yes" to the question about using the information to make comparisons, the questionnaire also included the questions "Is it possible to indicate a product with less impact to the environment through these comparisons?" and "How?". For both LCA- and EPD- information, approximately $67 \%$ of practitioners stated that "Yes" - it is possible, but with different methods and techniques applied by each of the practitioners. The 
answers to the question of how comparisons were performed were clustered into groups based on the free-text answers by the practitioners as illustrated in Figure 2. A detailed analysis of the underlying report and study is carried out by $40 \%$ of the practitioners that use EPD- and $24 \%$ comparisons, such as average data, best-in-class values and the worst-case scenario, was stated by $19 \%$ of the practitioners. Comparisons with similar products $(19 \%)$ and the use of the results from the impact assessment (19\%), including the use of specific Key Performance Indicators (KPIs) determined by the industry or the stakeholders (such as energy use and water consumption) were stated by practitioners that use EPD- information to perform comparisons. It was noted that practitioners seem to apply the comparisons in a specific way to try to meet this demand based on the personal or stakeholders' understanding of how to interpret the LCA- or the EPD-information. None of the respondents mentioned any rule or regulations that would have been followed in relation to these procedures.

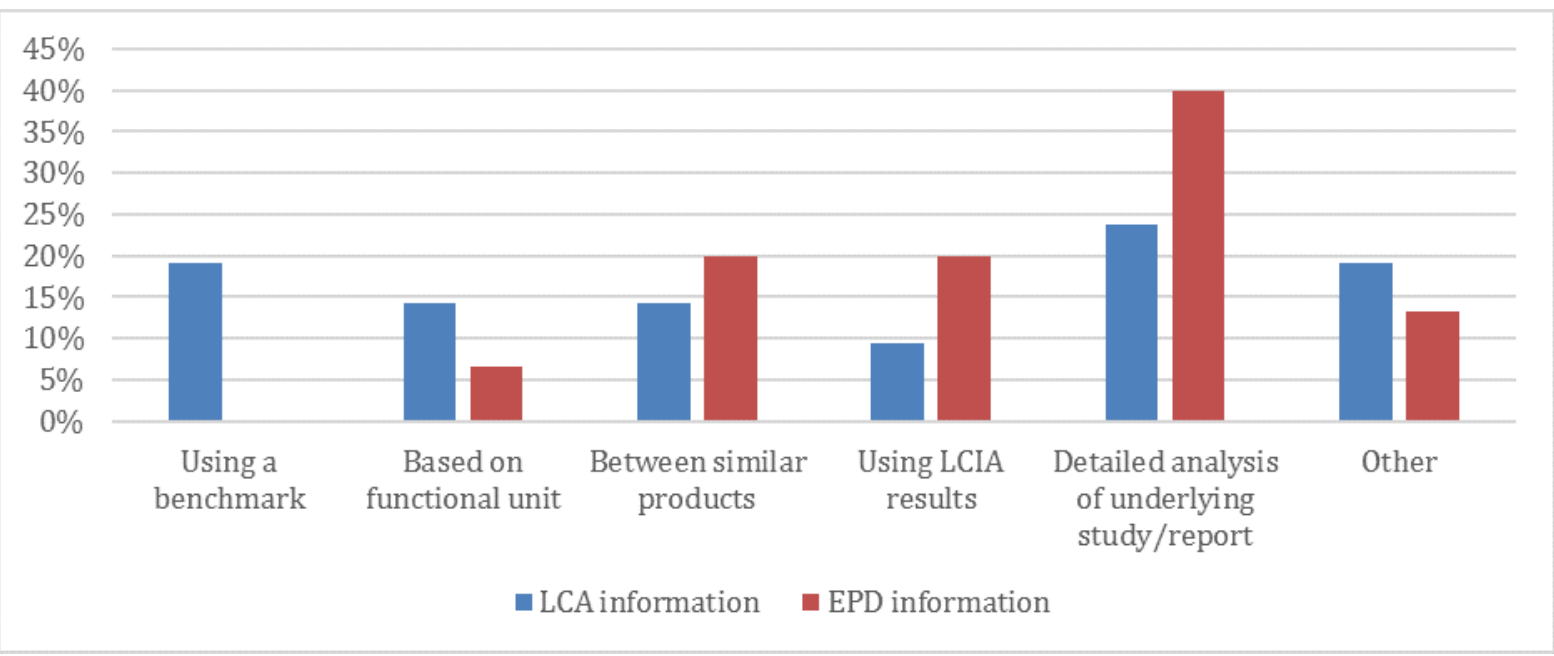

Figure 2. Different methods for performing comparisons based on various environmental information (in \% of the responses). Underlying data used to create this figure can be found in the Supporting Information.

Practitioners were also asked about the importance of common calculation rules for the comparability and the use of LCA and EPD information (see Figure 3). For each of the four situations (use of LCA-information; use of EPD-information; comparability of LCAinformation; and comparability of EPD-information), a ranking was attributed ranging from 1 "Not important at all" to 5 "Extremely important". Among all the situations presented, the comparability of EPD-information was the one where the use of common calculation rules was considered the most important, ranked 5 by $67 \%$ of practitioners and ranked 4 by $24 \%$. Next, to the comparability of LCA-information, the calculation rules were considered "5 - extremely important" by $61 \%$ of practitioners and " 4 - very important" by $30 \%$. For the "use of EPDinformation", the use of common calculation rules was ranked 5 by $39 \%, 4$ by $37 \%$ and 3 by $20 \%$ of the practitioners. In turn, for the "use of LCA-information" $39 \%$ practitioners considered the rules "5 - extremely important", $37 \%$ "4 - very important", and 20\% "3 - important". In general, the use of common calculation rules was considered more important for comparability than for use of LCA- and EPD- information and slightly more important for EPD- than for LCAinformation. This is reasonable, since EPDs are based on specific PCRs and their comparability 
is supported by applying the same calculation rules. The results of this question somewhat contrast with the practitioners' earlier answer, since while they consider common calculation rules to be important, they still use more LCA- than EPD-information in comparisons, as mentioned before.

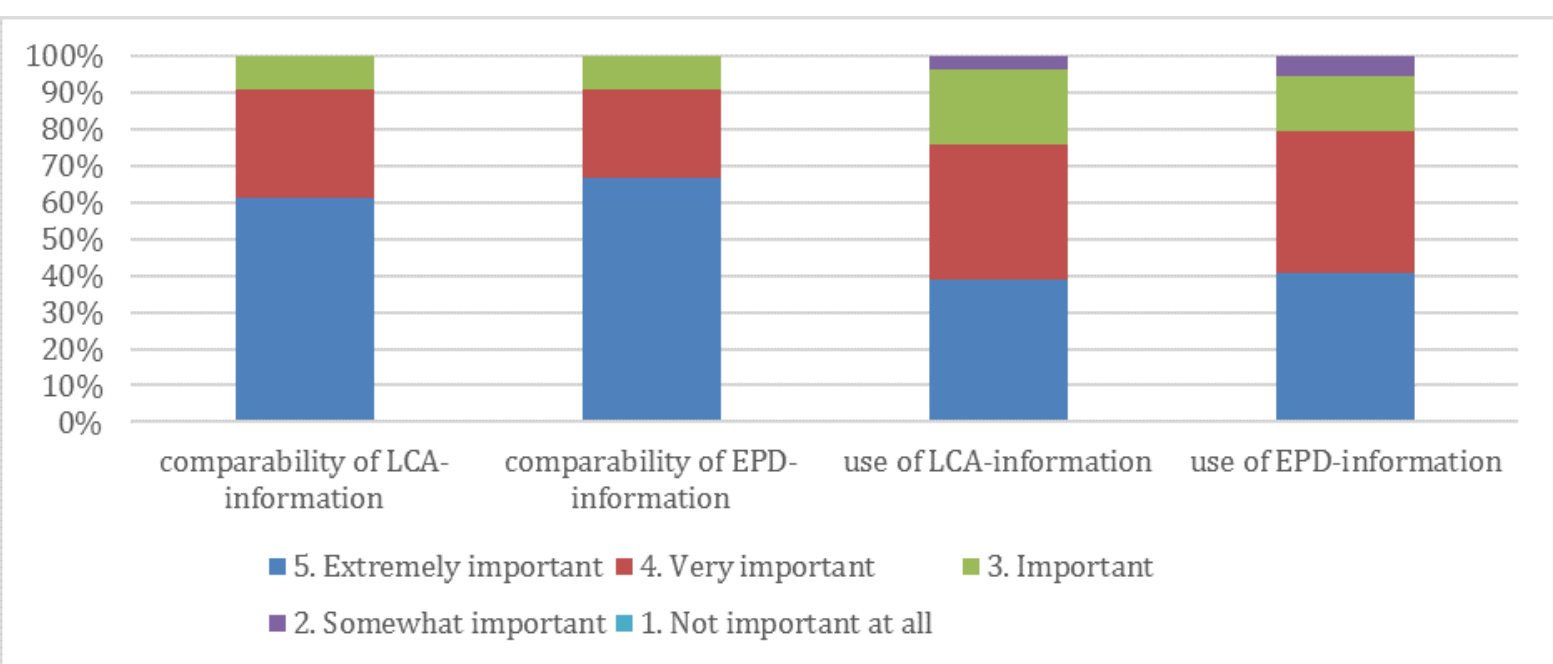

Figure 3. Importance of the use of common calculation rules, i.e. based on PCRs for the use and comparability of LCA- and EPD-information (in \% of the responses). Underlying data used to create this figure can be found in the Supporting Information.

Through the options of free text answers, practitioners were able to leave their opinions on the main advantages, disadvantages, strengths and weaknesses of using LCA- and EPDinformation. Regarding advantages and strengths, the main aspects indicated were Credibility / Transparency (38\% for LCA- and 35\% for EPD-information), Decision support / Understanding of the product (21\% for LCA and $27 \%$ for EPD-information) and Usability for comparisons ( $15 \%$ for LCA- and $31 \%$ for EPD-information). Regarding disadvantages and weaknesses, the main aspects indicated were Comparability issues (31\% for LCA- and 41\% for EPDinformation), Difficulties to understand and interpret results (23\% for LCA- and 17\% for EPDinformation), Uncertainty of results (21\% for LCA- and 7\% for EPD-information) and Methodological issues ( $8 \%$ for LCA- and 14\% for EPD-information). Figure 4 and Figure 5 show the detail of the answers given by the practitioners. Although they are indicated as credible and transparent information by many practitioners, it is noticed that once again the limitations of comparability are indicated by practitioners as points to be improved in the future developments of LCAs and EPDs. In addition, limitations in communication and in the understanding of the results and their significance are also mentioned and address issues observed in previous studies, such as Reap et al. (2008), Molina-Murillo and Smith (2009) and Galindro, Zanghelini and Soares (2019). It is worth noting that in relation to the uncertainties of the results, practitioners considered this limitation to be more related to LCA- than to EPD-information, which may indicate that there is a common understanding that PCRs play an important role for a proper understanding of the results. 


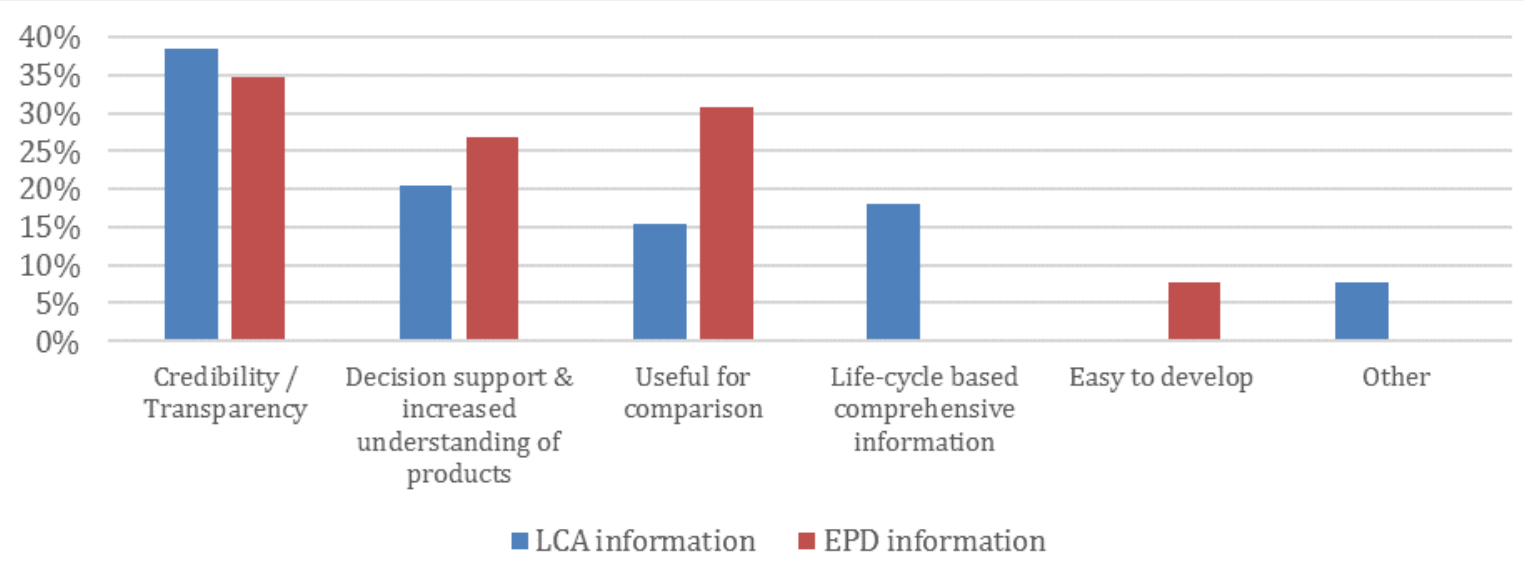

Figure 4. Advantages and strengths of LCA- and EPD-information (in \% of the responses). Underlying data used to create this figure can be found in the Supporting Information.

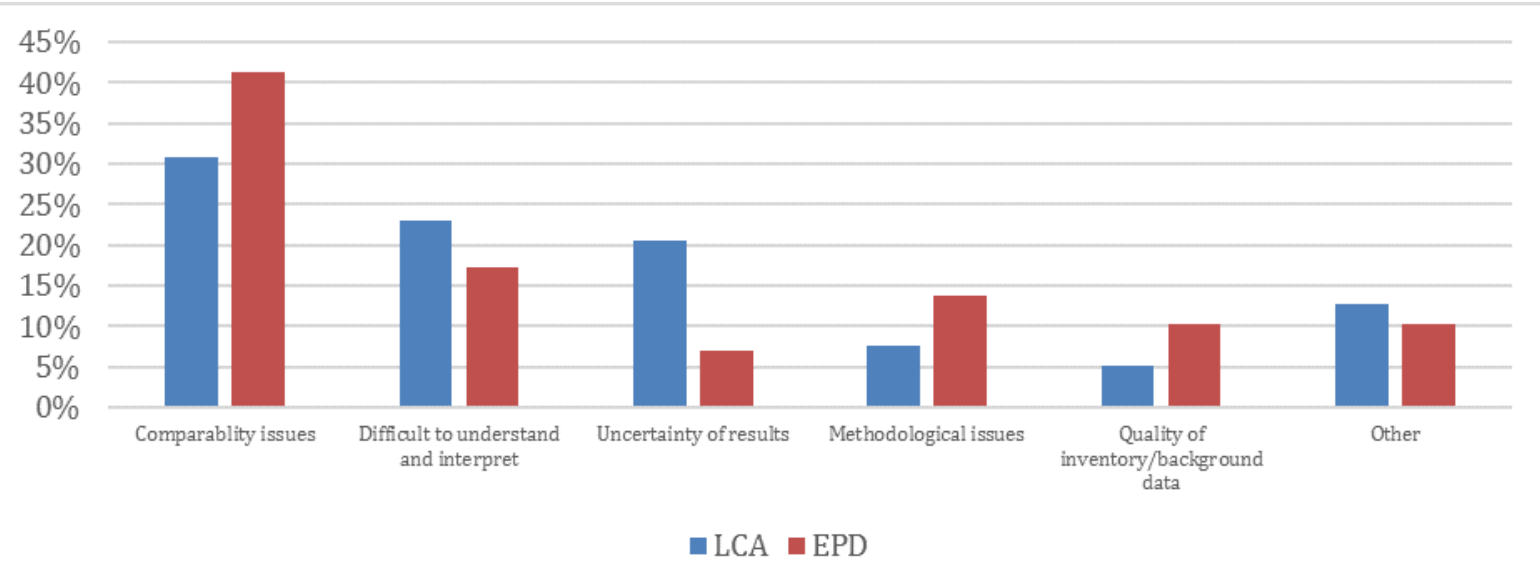

Figure 5. Disadvantages and weaknesses of LCA- and EPD-information (in \% of the responses). Underlying data used to create this figure can be found in the Supporting Information.

On the concept of credibility, practitioners were asked to evaluate 5 environmental communication options: LCA-information, EPD-information, environmental labels, own statements / self-declarations and other communication formats. For this, a scale of 5 levels of perceived credibility was presented: 1 - No credibility, 2 - Low credibility, 3 - Partial credibility, 4 - High credibility and 5 - Total credibility. Communication via EPD-information was considered to have the highest credibility, being evaluated positively (ranking 4 and 5 combined) by $70 \%$ of the practitioners. LCA-information was also positively assessed by $68 \%$ of the practitioners. In turn, the environmental labels were considered to have less credibility - 59\% of the practitioners. Self-declarations and other forms of communication were evaluated negatively, with rankings 1 and 2 combined by $78 \%$ and $68 \%$ of practitioners, respectively. The perception of the credibility and the classification into the presented scale may vary among the participants. Figure 6 shows the detail of practitioners' assessments of these communication options. 


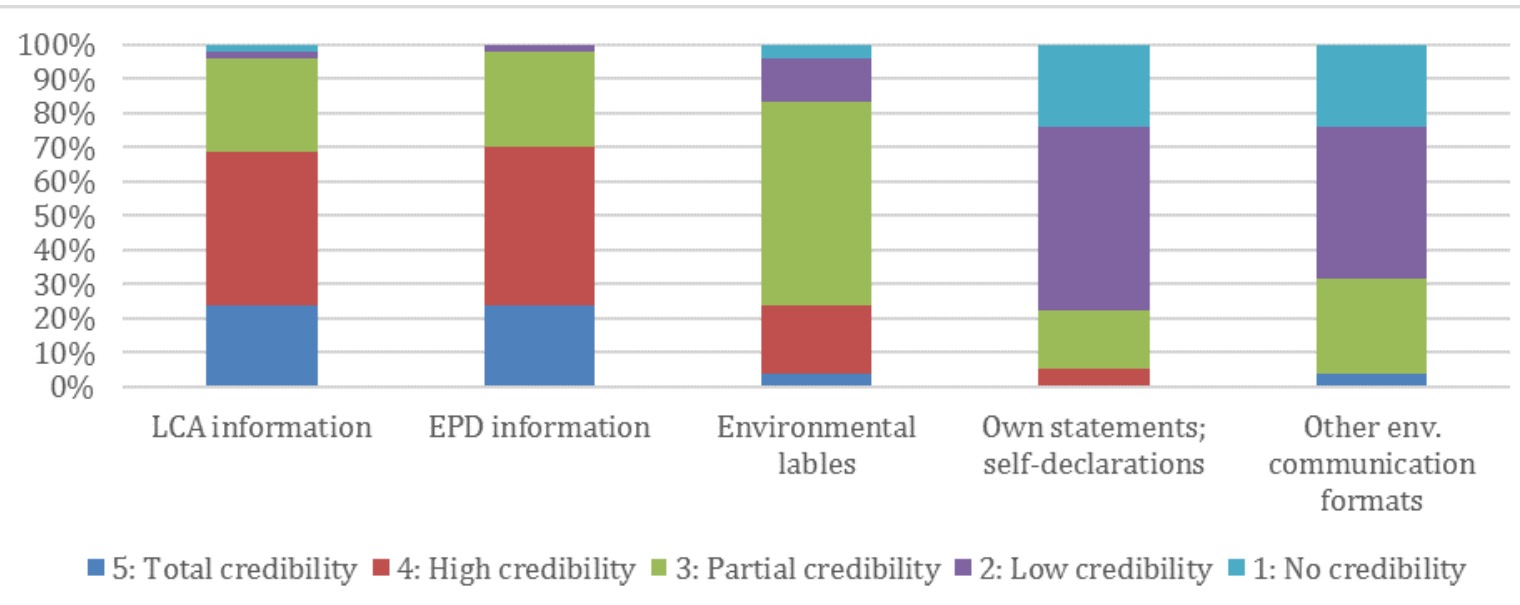

Figure 6. Evaluation of the credibility of different environmental communication options. Underlying data used to create this figure can be found in the Supporting Information.

Practitioners' views on the credibility of environmental labels as a communication option may be associated with a large proliferation of labels on the market with different approaches and methodologies with no further explanations, as indicated in the reports from the European Commission (2009, 2013a). Perceived credibility of single environmental labels may also differ, and answers could therefore vary for specific labels compared to labels in general. Because the respondents are mostly familiar with the LCA field, it is likely that they will consider the environmental communication options that directly involve this methodology as being more credible. However, the result indicates that despite limitations in making use of the comparisons and other related issues mentioned above, practitioners tended to prefer environmental communication options that were more closely related to a life-cycle perspective, with no significant variations between LCA- and EPD- information.

\section{PRESENTATION FORMATS AND BENCHMARKING FRAMEWORKS}

The second questionnaire was answered by 14 practitioners out of 55 possible respondents from the first questionnaire. This was to some extent expected since it was based on a follow-up from the first webinar where the benchmarking frameworks were presented.

Nonetheless, the results may provide an initial indication of the perceptions in this target group. Conducting further studies including a larger number of respondents and broader geographical coverage may give a more comprehensive view to the findings of this study. The composition of the practitioners that responded to the survey showed a majority of European representatives (71\%), with organizational positions of researchers $(50 \%)$ and consultants (14\%) working in the education $(36 \%)$ and manufacturing $(29 \%)$ sectors.

In this second questionnaire, participants were asked to indicate preferred types of application for six different presentation formats of LCA- or EPD-information. Multiple applications types could be chosen for each presentation format (e.g. mass- and energy flows could be indicated for preferred use within B2B communication and internal use). The results are presented Figure 7, where (1) results describe mass- and energy flows in an inventory table, (2) detailed flow schemes covering inputs and outputs to and from all unit processes, (3) information about environmental problems for different so-called environmental impact categories, (4) specific information on "single issue" communication formats such as Carbon Footprint, (5) 
results from "hot-spot analyses" giving a rough indication of the extent of the potential environmental impact in the various stages of a product's life cycle, and (6) as an aggregated and weighed assessment of the total environmental impact expressed in simple quantitative ways indicated by ranges and simple scales using different colors.

In general, the practitioners considered all the presentation formats appropriate for internal use, highlighted as the most appropriate use for five of the six formats. In addition, it may be noted that the simpler presentation formats (e.g. aggregated single scores and hot-spot analyses) were considered more appropriate to perform comparisons and benchmarking. However, none of the suggested formats was generally recommended by most practitioners for use directed to non-specialist audiences such as certification/labelling schemes, business-tobusiness (B2B) and business-to-consumer (B2C) communication.

(6) Aggregated scores

(5) Hot-spot analyses

(4) Single issue formats

(3) Info. about impact categories

(2) Detailed Flow schemes

(1) Mass - energy flows

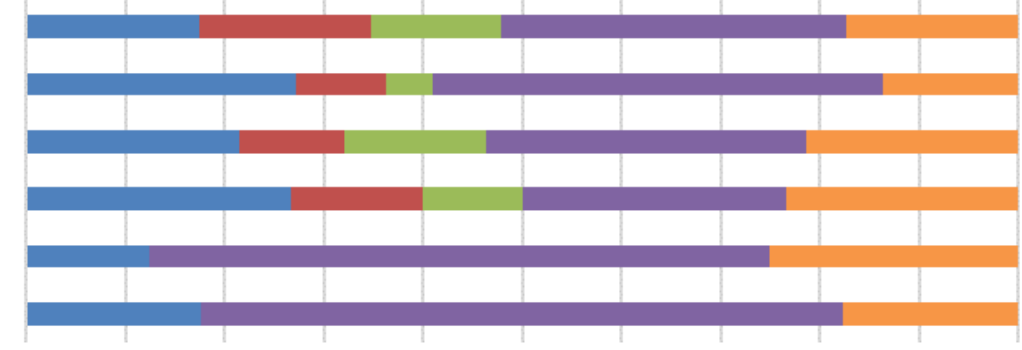

$$
\begin{aligned}
& \begin{array}{lllllllllll}
0 \% & 10 \% & 20 \% & 30 \% & 40 \% & 50 \% & 60 \% & 70 \% & 80 \% & 90 \% & 100 \%
\end{array} \\
& \text { - B2C communication } \quad \text { Public procurement } \\
& \text { —Comparison / benchmarking « Certification / labelling schemes }
\end{aligned}
$$$$
\text { - B2B communication }
$$$$
\text { - Internal use }
$$

Figure 7. Types of applications for different presentation formats for LCA- and EPDinformation. Underlying data used to create this figure can be found in the Supporting Information.

When practitioners were asked "Is it able to develop a fair benchmark based on products of the same product category, as defined in product category rules, used to develop EPDs?", the responses were divided in their understanding since 50\% answered "Yes" and 50\% answered "No". Among the limitations in the development of benchmarks, issues regarding the consistency of the databases used, variations of the boundaries of the evaluated system, methodological choices (such as the adopted emission factors) and the granularity of product categories were all mentioned. In general, some problems pointed out seem to be especially related to the need for harmonization and consistency of PCRs, as well as the understanding of some practitioners that products within the same product category are not comparable because they may have different functions. However, some practitioners claimed that it is not possible to find an ideal solution and that a benchmark initiative can contribute to a better comparability of EPD-information and support decision making, since they have been developed for the same PCRs.

Although the number of survey respondents is very small compared to the initial target audience, the overall opinions of the practitioners in the second questionnaire seem to present similarities with the questions already pointed out by some previous studies such as Fet and Skaar (2006), Ingwersen and Stevenson (2012), Modahl et al. (2013), Hunsager et al. (2014), Minkov et al. (2015) and Ibáñez-Forés et al. (2016) regarding the need to increase efforts to 
harmonize PCRs. Such an attempt should preferably establish common calculation rules that meet the specifications of each product category and provide a detailed framework of guidelines and procedures to be adopted for robust communication. Despite the efforts already made in the harmonization of the PCRs, such as the publication of the Guidance for Product Category Rule Development (GPCRD) (Ingwersen \& Subramanian 2014), the development of the technical standard ISO/TS 14027:2017 (ISO 2017) and recent initiatives to harmonize Mutual Recognition Agreements (MRA), some of the practitioners seem to consider that the use of EPD-information for comparison and benchmarking is still somewhat limited.

Regarding the feedback of the benchmarking frameworks presented (see Supporting Material), $43 \%$ of the respondents considered the work of Welling and Ryding (2019) to be applicable in B2B communication and Eco-design. B2B communication, marketing, policymaking, public procurement and research were considered by $36 \%$ of the respondents as important application areas for broader applications. Despite the fact that variations in the communication formats facilitate meeting a number of needs for different audiences of the environmental information, the foundation elements for the comparability, e.g. functional unit, system boundaries and other underlying calculation rules of the information were all identified as key aspects for the applicability of the benchmarking proposal. A further regional or productspecific division of the properties is suggested by the respondents of the study, as well as consideration of geographical validity and time representativeness of the results. $57 \%$ of the practitioners considered the proposal of Welling and Ryding (2019) feasible for application in different product categories. It is stated that due to the current lack of data within other product categories, the applicability may increase with greater availability of LCA- and EPDinformation.

The benchmarking framework suggested in Galindro, Bey et al. (2019) was considered to be applicable in $\mathrm{B} 2 \mathrm{C}$ communication by $43 \%$ of practitioners, and in product comparisons by $36 \%$ and in research by $29 \%$ of respondents. In general, despite considering the proposal complex and requiring more information for a better understanding of the framework, $64 \%$ of practitioners may consider the proposal somewhat applicable for application in different product categories. Because the benchmarking framework of Galindro, Bey et al. (2019) is based on a linear programming methodology, there are some procedures and considerations that need to be presented in further details. This may have caused the difficulty in understanding the framework by the practitioners, once they were introduced to the concepts through the webinar presentation. It is expected that further dissemination of the proposal will make its content more clear as well as improve its feasibility for implementation. In any case, this suggested framework was perceived as having the potential to contribute to communication and make the results more clear for non-specialist audiences.

In terms of potentials to promote and facilitate the interpretation and use of LCA- and EPD-information in the future, practitioners were asked to evaluate five different options: Product Environmental Footprint (PEF); ECO Platform; International harmonization and standardization efforts; Digitalization of LCA and EPD information; and MRA (see Supporting Material for further information and references). Each of the options listed could be evaluated separately, considering that the listed options may cover different aspects and also overlap with each other. Some of the practitioners considered that international harmonization and standardization efforts, MRA between program operators and digitalization of LCA- and EPDinformation have potential for practical use, being indicated as high or total potential by $64 \%$, $57 \%$ and $50 \%$ of practitioners, respectively (Figure 8 ). These initiatives are evaluated to have 
greater potential compared to the remaining options, such as PEF (European Commission, 2013b) and ECO Platform (2019). However, it is worth mentioning that the question of harmonization and standardization seems to arise as a very recurrent demand by practitioners, together with other initiatives with complementary objectives.

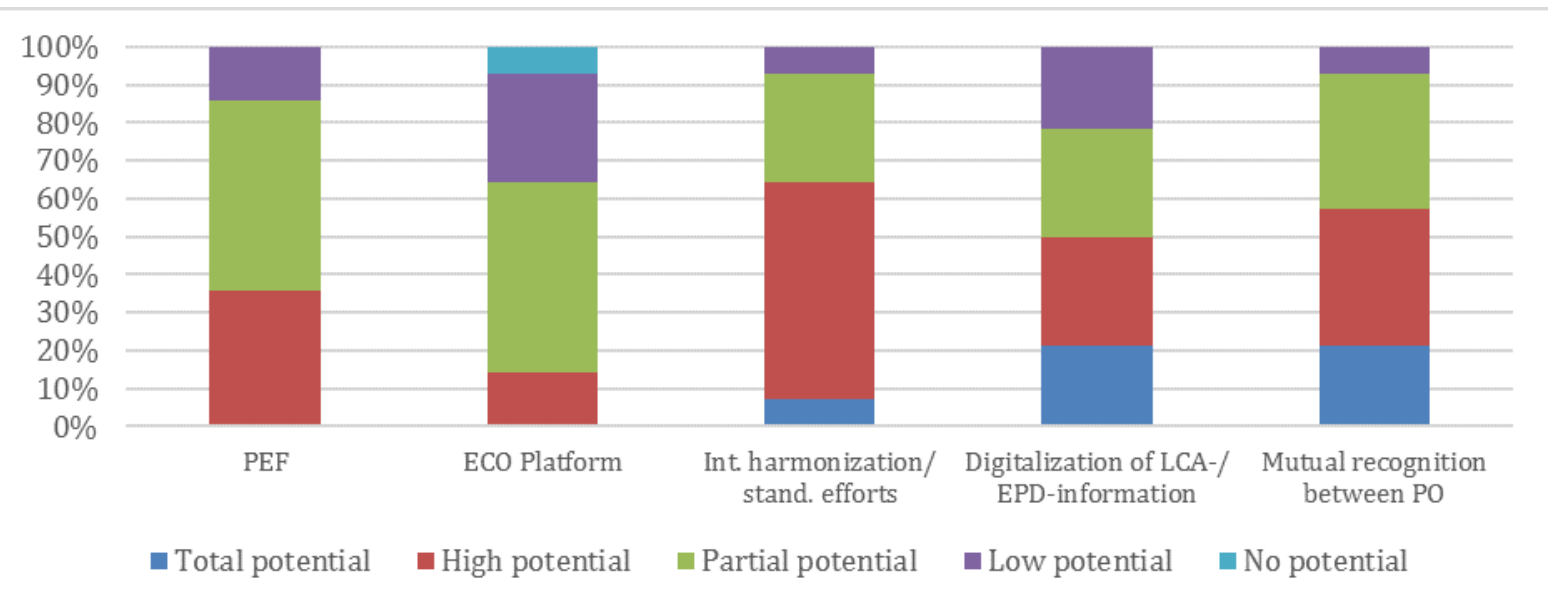

Figure 8. Potentials of selected options to promote future interpretation and use of LCA- and EPD- information. Underlying data used to create this figure can be found in the Supporting Information.

\section{CONCLUSIONS}

This article describes results from a study that intended to understand how environmental information from LCAs and EPDs are used by different practitioners. Through two online questionnaires, stakeholders were able to provide their views about the reliability, use, and application of the results of LCA- and EPD-information. The study also captured practitioners' opinions and suggestions on suitable ways to present the information, as well as their feedback on two suggested frameworks for benchmarking, via two webinars.

Regarding the reliability of LCA- and EPD- information, practitioners generally have a positive view regarding the usefulness and applicability of these types of data, being somewhat more pronounced for LCA-information. Results from LCA and EPD studies can be used for different applications, such as marketing, public procurement, communication, environmental management, and strategic development. In these applications, LCA- and EPD- information are generally considered more reliable when compared to other forms of environmental communication, such as ecolabels and self-declarations. LCA is broadly seen as a more robust methodology and is suggested to be used more widely in several practical market applications.

The practitioners' general perception showed that the LCA-information is applied even when comparing the environmental performance of products, which is not necessarily the main focus of LCA, according to relevant international standards. EPD-information is also used for such comparisons, but to a lesser extent than for LCA-information, which was claimed as being due to the limited use of common calculation rules. Common calculation rules are very important both for the use and comparability of results from LCA- and EPD-information, emphasizing the need for more harmonization efforts when developing PCRs. This article indicates that comparing the environmental performance of products, despite current limitations, is a recurrent 
activity among practitioners. The perceived lack of official guidance tends to increase diversification of initiatives in terms of the use of specific procedures and techniques for calculations and comparisons. It is therefore important that efforts are made to guide harmonization of PCRs so that comparisons based on EPD-information can be carried out in an appropriate, transparent and fair manner.

The second questionnaire indicated a tendency for agreement among practitioners regarding communication aimed at non-specialist audiences (B2B and $\mathrm{B} 2 \mathrm{C}$, for example), that simpler presentation formats such as aggregated single scores or unique indicators should be preferred. Benchmarking frameworks proposed by the authors in previous studies, were pointed out as having good potential for being implemented for both $\mathrm{B} 2 \mathrm{C}$ communication and for use in certification/labelling schemes. Limitations were mentioned also for these types of applications based on EPD data due to the need to increase harmonization and common calculation rules, which underlines the need for progress to overcome some of the limitations. However, the limited number of respondents to the questionnaire does not allow a dedicated in-depth analysis on the validation of the proposals, requiring a greater dissemination and presentation of these proposals for a wider range of practitioners in the future.

The comparatively low number of respondents of the first and especially of the second questionnaire is a limiting factor for the analysis of the results drawn in this study. The approach taken in this study, even though it is practical and cost-effective to be able to receive inputs from experts on a global scale, limits responses to participants who are willing to fill the forms and attend webinars. Other approaches such as hosting workshops or organizing side events for specific purposes at conferences could increase response rates but could also result in limiting the study's respondents only to certain stakeholders who attend international events. For future studies, including non-practitioners could provide broader perspectives on the use of LCA- and EPD-information. Nevertheless, this study still allowed to infer that practitioners may demand more comparability. It was also possible to gain some understanding of the practitioners' practice and capture some of their future needs towards LCA and EPD application.

\section{REFERENCES}

Bernardi, E., Carlucci, S., Cornaro, C., \& Bohne, R. A. (2017). An analysis of the most adopted rating systems for assessing the environmental impact of buildings. Sustainability (Switzerland), 9(7), 1-27. https://doi.org/10.3390/su9071226

Bienert, S., Geiger, P., \& Hirsch, J., 2017. Grün kommt! Europäische Nachhaltigkeitsstatistik 2017, Frankfurt am Main: RICS Deutschland.

Bovea, M. D., Ibáñez-Forés, V., \& Agustí-Juan, I. (2014). Environmental product declaration (EPD) labelling of construction and building materials. In Eco-Efficient Construction and Building Materials (pp. 125-150). https://doi.org/http://dx.doi.org/10.1533/9780857097729.1.125

Brinkmann, T., Köhler, S., Boeth, A., Metzger, L., 2018. Environmental Product Declarations. Benefits, Expectations and Fulfilments - A Stakeholder View. Part 1. Retrieved from: https://www.brandsandvalues.com/study1-epd-environmentalproductdecl 
Del Borghi, A. (2013). LCA and communication: Environmental Product Declaration. International Journal of Life Cycle Assessment, 18(2), 293-295. https://doi.org/10.1007/s11367012-0513-9

ECO Platform (2019). Welcome to ECO Platform. Retrieved from: https://www.ecoplatform.org/.

European Commission. (2009). Europeans' attitudes towards the issue of sustainable consumption and production: analytical report. Luxembourg: Office for Official Publications of the European Communities.

European Commission. (2013a). Attitudes of Europeans towards building the single market for green products. Luxembourg: Office for Official Publications of the European Communities.

European Commission. (2013b). Communication from the commission to the European Parliament and the Council. Building the Single Market for Green Products Facilitating better information on the environmental performance of products and organisations. Luxembourg: Office for Official Publications of the European Communities.

Fet, A. M., \& Skaar, C. (2006). Eco-labeling, Product Category Rules and certification procedures based on ISO 14025 requirements. The International Journal of Life Cycle Assessment, 11(1), 49-54. https://doi.org/10.1065/lca2006.01.237

Fet, A. M., Skaar, C., \& Michelsen, O. (2009). Product category rules and environmental product declarations as tools to promote sustainable products: Experiences from a case study of furniture production. Clean Technologies and Environmental Policy, 11(2), 201-207. https://doi.org/10.1007/s10098-008-0163-6

Galindro, B. M., Bey, N., Olsen, S. I., Fries, C. E., \& Soares, S. R. (2019). Use of Data Envelopment Analysis to benchmark Environmental Product Declarations - a suggested framework. International Journal of Life Cycle Assessment. https://doi.org/ 10.1007/s11367019-01639-1

Galindro, B. M., Zanghelini, G. M., \& Soares, S. R. (2019). Use of benchmarking techniques to improve communication in life cycle assessment: A general review. Journal of Cleaner Production, 213, 143-157. https://doi.org/10.1016/j.jclepro.2018.12.147

Gelowitz, M. D. C., \& McArthur, J. J. (2016). Investigating the Effect of Environmental Product Declaration Adoption in LEED® on the Construction Industry: A Case Study. Procedia Engineering. https://doi.org/10.1016/j.proeng.2016.04.014

Gelowitz, M. D. C., \& McArthur, J. J. (2017). Comparison of type III environmental product declarations for construction products: Material sourcing and harmonization evaluation. Journal of Cleaner Production, 157, 125-133. https://doi.org/10.1016/j.jclepro.2017.04.133. 
Guinée, J. B. (2002). Handbook on Life Cycle Assessment, Operational Guide to the ISO Standards. Geneva, Switzerland: Springer.

Hauschild, M.Z.; Rosenbaum, R.K.; Olsen, S.I. (2018) Life Cycle Assessment: theory and practice. Geneva, Switzerland: Springer.

Hunsager, E. A., Bach, M., \& Breuer, L. (2014). An institutional analysis of EPD programs and a global PCR registry. The International Journal of Life Cycle Assessment, 19(4), 786-795. https://doi.org/10.1007/s11367-014-0711-8

Ibáñez-Forés, V., Pacheco-Blanco, B., Capuz-Rizo, S. F., \& Bovea, M. D. (2016).

Environmental Product Declarations: exploring their evolution and the factors affecting their demand in Europe. Journal of Cleaner Production, 116, 157-169. https://doi.org/10.1016/j.jclepro.2015.12.078

Ingwersen, W. W., \& Stevenson, M. J. (2012). Can we compare the environmental performance of this product to that one? An update on the development of product category rules and future challenges toward alignment. Journal of Cleaner Production, 24, 102-108. https://doi.org/10.1016/j.jclepro.2011.10.040

Ingwersen, W.W. and V. Subramanian. 2014. Guidance for product category rule development: process, outcome, and next steps. The International Journal of Life Cycle Assessment 19(3): $532-537$.

ISO 14020:2000 (2000) International standard - Environmental labels and declarations General principles. International Organization for Standardization. Geneva, Switzerland

ISO 14025:2006 (2006a) International standard - Environmental labels and declarations. Type III environmental declarations - principles and procedures. International Organization for Standardization. Geneva, Switzerland

ISO 14040:2006 (2006b) International standard - Environmental Management - Life Cycle Assessment - Principles and Framework. International Organization for Standardization. Geneva, Switzerland

ISO 14044:2006 (2006c) International standard - Environmental Management - Life Cycle Assessment - Requirements and Guidelines. International Organization for Standardization. Geneva, Switzerland

ISO/TS 14027:2017 (2017) International standard — Environmental labels and declarations Development of product category rules. International Organization for Standardization. Geneva, Switzerland

Minkov, N., Schneider, L., Lehmann, A., \& Finkbeiner, M. (2015). Type III Environmental Declaration Programmes and harmonization of product category rules: Status quo and practical 
642

643

644

645

646

647

648

649

650

651

652

653

654

655

656

657

658

659

660

661

662

663

664

665

666

667

668

669

670

671

672

673

674

675

676

677

678

679

680

681

682

683

684

685

686 challenges. Journal of Cleaner Production, 94, 236-246.

https://doi.org/10.1016/j.jclepro.2015.02.012

Modahl, I. S., Askham, C., Lyng, K. A., Skjerve-Nielssen, C., \& Nereng, G. (2013). Comparison of two versions of an EPD, using generic and specific data for the foreground system, and some methodological implications. International Journal of Life Cycle Assessment, 18(1), 241-251. https://doi.org/10.1007/s11367-012-0449-0

Molina-Murillo, S. A., \& Smith, T. M. (2009). Exploring the use and impact of LCA-based information in corporate communications. International Journal of Life Cycle Assessment, 14(2), 184-194. https://doi.org/10.1007/s11367-008-0042-8

Passer, A., Lasvaux, S., Allacker, K., De Lathauwer, D., Spirinckx, C., Wittstock, B., Kellenberger, D., Gschösser, F., Wall, J., Wallbaum, H. (2015). Environmental product declarations entering the building sector: critical reflections based on 5 to 10 years experience in different European countries. International Journal of Life Cycle Assessment, 20(9), 1199-1212. https://doi.org/10.1007/s11367-015-0926-3

Reap, J., Roman, F., Duncan, S., \& Bras, B. (2008). A survey of unresolved problems in life cycle assessment. Part 1: Goal and scope and inventory analysis. International Journal of Life Cycle Assessment, 13(4), 290-300. https://doi.org/10.1007/s11367-008-0008-x

Rex, E., Fernqvist, N., Ryding, S-O, 2019. Recommendation and context: the missing links for increased life cycle impact in large industry organisations. Submitted to International Journal of Life Cycle Assessment.

Sala, S., \& Andreasson, J. (2018). Improving Interpretation, Presentation and Visualisation of LCA Studies for Decision Making Support. In: E. Benetto, K. Gericke, \& M. Guiton (Eds.), Designing Sustainable Technologies, Products and Policies: From Science to Innovation (pp. 337-342). https://doi.org/10.1007/978-3-319-66981-6_37

Stevenson, M. J., \& Ingwersen, W. W. (2012). Environmental Product Claims and Life Cycle Assessment. In M. A. Curran (Ed.), Life Cycle Assessment handbook: a guide to environmentally sustainable products (pp. 475-543).

https://doi.org/10.1002/9781118528372.ch22

Testa, F., Nucci, B., Tessitore, S., Iraldo, F., \& Daddi, T. (2016). Perceptions on LCA implementation: evidence from a survey on adopters and nonadopters in Italy. International Journal of Life Cycle Assessment, 21(10), 1501-1513. https://doi.org/10.1007/s11367-016-11069

Toniolo, S., Mazzi, A., Simonetto, M., Zuliani, F., \& Scipioni, A. (2019). Mapping diffusion of Environmental Product Declarations released by European program operators. Sustainable Production and Consumption, 17, 85-94, https://doi.org/10.1016/j.spc.2018.09.004. 
687 Welling, S., Ryding, S-O., 2019. Making use of LCA- and EPD-information in Market

688 Applications: Statistical Analyses of the distribution of environmental performance of products

689 in the food- and construction sector. Submitted to International Journal of Life Cycle

690 Assessment.

691

692

693

694

695

696

\section{SUPPORTING INFORMATION}

697

The supporting information provides the two questionnaires that were applied to the 698 practitioners, along with the links to the two webinars in which the benchmarking framework (Galindro, Bey et al., 2019; Welling \& Ryding, 2019) were presented and discussed. 